\section{ARCHIVE WILL DOCUMENT EVOLUTION OF THE PROFESSION}

A bequest from former British Dental Association (BDA) president John Walford McLean OBE, who served from 19941995 , is to be used to fund work on an archive documenting the history of dentistry since the start of the NHS. The John McLean Archive: A Living History of Dentistry is being developed in conjunction with King's College London Dental Institute's Unit for the History of Dentistry.

Members of the McLean family presented the BDA Trust Fund with a cheque in support of dental research, which will be used to fund the archive, at a reception held at the BDA headquarters in London. The project will comprise a series of witness seminars and individual oral history interviews, and encompass the full breadth of dentistry in the UK.

'In time, this archive will provide an essential record of the significant evolution of the dental profession from 1948 onwards,' said Head of BDA Museum Services, Rachel Bairsto. 'We are honoured to be given the opportunity to realise this project through the generosity of one of the most highly-regarded leaders in the profession, John McLean.'

\section{MPs AND PEERS EXPERIENCE LEARNING AT KCLDI}

A visit by the All-Party Parliamentary Group (APPG) for Dentistry to King's College London Dental Institute (KCLDI) in March highlighted to MPs and Peers the role played by the UK's dental schools.

The visitors were able to observe the work of a busy dental school, including its research, teaching and clinical activities. Guests were able to visit KCLDI's craniofacial development and stem cell research laboratories, tour facilities for the care of vulnerable and anxious patients and see the stateof-the-art hapTEL technology used in teaching students.

The relationship between quality and continued funding and the breadth of research being carried out was explained during the visit, which was led by Professor Nairn Wilson, Professor of Restorative Dentistry and Dean and Head of KCLDI. The increasing links with industry that are helping to deliver millions of pounds of income were also emphasised.

Fourth year student and President of KCLDI's Dental Society Lauren Holmes highlighted the experience of dental students and stressed the importance of the reforms currently being undertaken in dentistry engaging the next generation of practitioners who will deliver care in the system that is created.

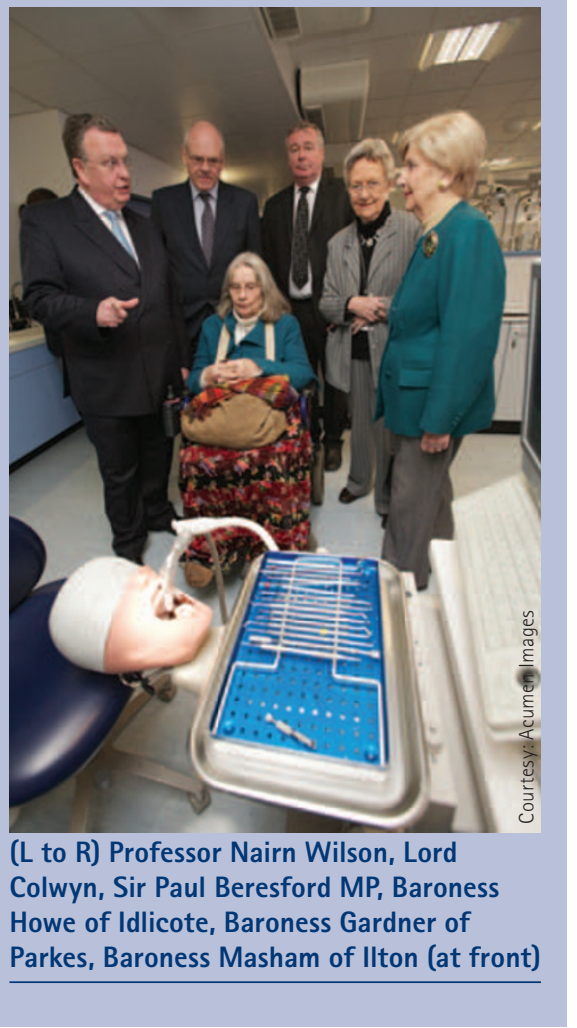

\title{
GIVE PAIN RELIEF IN THE PUNJAB
}

The Rotary Clubs of Mill Hill in London and Sirhind in the Punjab, India are calling for volunteer dental professionals for the Pain Relief Dental Clinic which they helped establish in Hansali, India.

Hansali is a small village in the heart of rural Punjab, North West India and home to 220 people. Access to any type of medical care, including dental treatment, is unaffordable or inaccessible to villagers. The Pain Relief clinic was set up in February 2009 and serves as a primary care facility available free of charge to the local community. With three permanent staff, the clinic has treated over 80,000 patients in the last 12 years.

Visiting volunteer dental professionals stay at the clinic for periods from one week to one month, treat patients and share their experience and technical expertise with the local staff. Most visitors pay their own way although air-conditioned accommodation and vegetarian food are provided.
If any dentists, dental nurses or dental hygienists are interested in volunteering at the clinic, email Mr Coonar on hscoonar@ hotmail.com or telephone 02084401860.

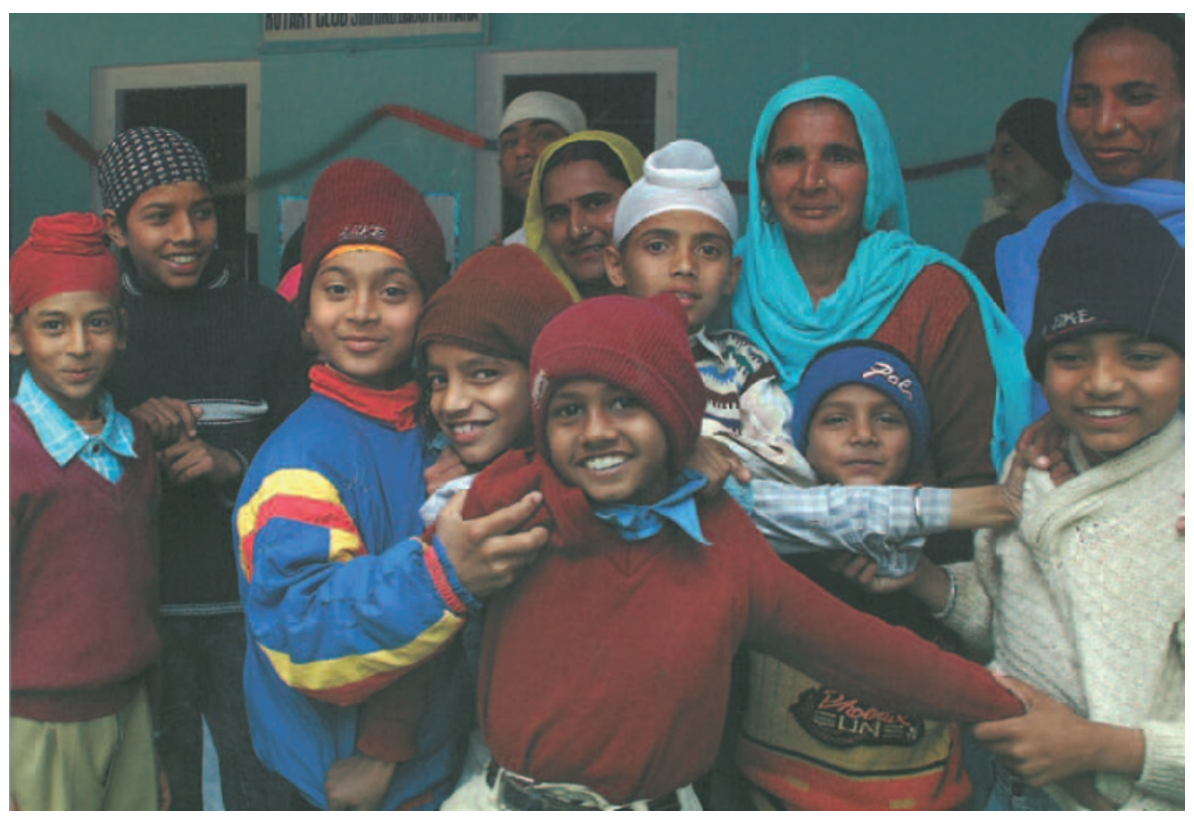

